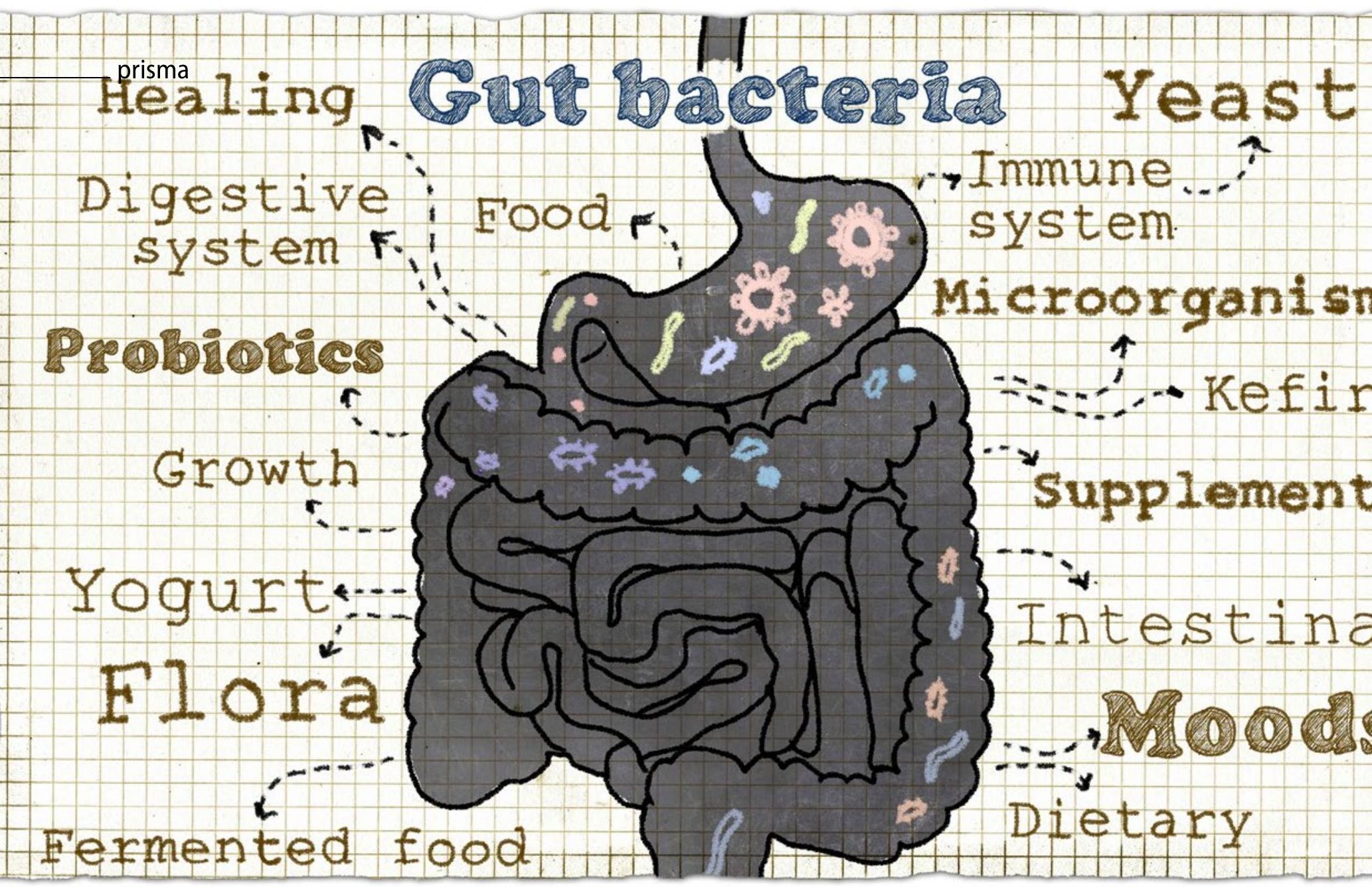

Mikrobiom-Glosse

\title{
Bakterien sind Alleskönner
}

Wer hätte das gedacht? Noch vor Kurzem galten sie als der Feind der Gastroenterologen: Die Rede ist von Bakterien, über die man früher nur im Zusammenhang mit Magen-Darm-Infektionen sprach. Und diese gelten ja bekanntlich nicht als aristokratische Krankheitsbilder. Da hat die Gastroenterologie jetzt aber eine $180^{\circ}$-Wendung vollzogen. Wer den diesjährigen Kongress der Deutschen Gesellschaft für Verdauungs- und Stoffwechselkrankheiten (DGVS) in Dresden besuchte, konnte sich des Eindruckes nicht erwehren, als gebe es nur noch ein einziges interessantes Forschungsgebiet, nämlich das der Darmflora. Doch die Terminologie ist akademisch betrachtet eigentlich nicht korrekt; denn Bakterien sind genau genommen keine Pflanzen, also müsste es eher „Darmfauna“ heißen. Aber so richtige Tiere sind es wieder auch nicht. Vielleicht kann man sich auf „Flaura“ einigen.

\section{Plötzlich Lieblinge der Gastroenterologen}

Doch warum sind die Darmbakterien ganz plötzlich zum Liebling der Gastroenterologen mutiert? Ganz einfach: Die falschen Bakterien machen dick, dumm, hässlich, faul, krank und depressiv. Umgekehrt wird dadurch den Magen-Darm-Spezialisten die wundersame und wunderbare Fähigkeit verliehen, ihre Patienten gesund, schlank, schön und schlau machen zu kön- nen. Also all das, was die Medizin bisher nicht wirklich vermochte. Glaubt man den Studien, so gibt es kaum ein gastroenterologisches oder hepatologisches Krankheitsbild, an dem nicht mittel- oder zumindest unmittelbar die Bakterien schuld sind: Reizmagen, Reizdarm, bakterielle Fehlbesiedlung, Divertikulose, NSAR-Enteropathie, chronisch entzündliche Darmerkrankungen etc. Dabei ist nicht die Menge an Bakterien, sondern die Typenvielfalt das Entscheidende. Je mehr Sorten im Darm, umso gesünder ist der Mensch. Und wer nur wenige Spezies aufzuweisen hat, ist sehr arm dran.

\section{Therapeutische Zauberformel}

So lautet die therapeutische Zauberformel: Mikrobiommodulation. Welch schöner Begriff für eine so ekelige, um nicht zu sagen anrüchige Sache. Doch dahinter verbirgt sich ein heroisch anmutendes Therapiekonzept, nämlich das der fäkalen Stuhltransplantation. Darunter versteht man die Übertragung der Stuhlbakterien von einem Gesunden auf einen Kranken. Die Sache scheint gut zu funktionieren. Nur mit der Akzeptanz gibt es noch Probleme. Doch Böses muss man eben mit Bösem vertreiben. Und entscheidend ist schließlich, was hinten dabei rauskommt.

Dr. med. Peter Stiefelhagen 